\title{
Article
}

\section{The Quebec Newborn Twin Study at 21}

\author{
Michel Boivin ${ }^{1}$, Mara Brendgen², Ginette Dionne ${ }^{1}$, Isabelle Ouellet-Morin ${ }^{3}$, Lise Dubois ${ }^{4}$, Daniel Pérusse ${ }^{5}$, \\ Philippe Robaey ${ }^{6}$, Richard E. Tremblay ${ }^{7}$ and Frank Vitaro ${ }^{8}$ \\ ${ }^{1}$ School of Psychology, Université Laval, Québec, Canada, ${ }^{2}$ Department of Psychology, Université du Québec à Montréal, Montréal, Québec, Canada, ${ }^{3}$ School of \\ Criminology, Université de Montréal, Montréal, Québec, Canada, ${ }^{4}$ Faculty of Medicine, University of Ottawa, Ottawa, Ontario, Canada, ${ }^{5}$ Department of \\ Anthropology, Université de Montréal, Montréal, Québec, Canada, ${ }^{6}$ Department of Psychiatry, University of Ottawa, Ottawa, Ontario, Canada, ${ }^{7}$ Department of \\ Pediatrics and Psychology, Université de Montréal, Montréal, Québec, Canada and ${ }^{8}$ School of Psycho-Education, Université de Montréal, Montréal, Québec, \\ Canada
}

\begin{abstract}
This paper is a revised and updated edition of a previous description of the Quebec Newborn Twin Study (QNTS), an ongoing prospective longitudinal follow-up of a birth cohort of twins born between 1995 and 1998 in the greater Montreal area, Québec, Canada. The goal of QNTS is to document individual differences in the cognitive, behavioral, and social-emotional aspects of developmental health across childhood, their early genetic and environmental determinants, as well as their putative role in later social-emotional adjustment, school, health, and occupational outcomes. A total of 662 families of twins were initially assessed when the twins were aged 6 months. These twins and their family were then followed regularly. QNTS now has 16 waves of data collected or planned, including 5 in preschool. Over the last 24 years, a broad range of physiological, cognitive, behavioral, school, and health phenotypes were documented longitudinally through multi-informant and multimethod measurements. QNTS also entails extended and detailed multilevel assessments of proximal (e.g., parenting behaviors, peer relationships) and distal (e.g., family income) features of the child's environment. QNTS children and a subset of their parents have been genotyped, allowing for the computation of a variety of polygenic scores. This detailed longitudinal information makes QNTS uniquely suited for the study of the role of the early years and gene-environment transactions in development.
\end{abstract}

Keywords: longitudinal twin study; gene-environment transactions; infancy; preschool; social-emotional development; peer relationships; language; numeracy; school readiness and achievement

(Received 6 June 2019; accepted 27 June 2019; First Published online 21 October 2019)

This article is a revised and updated edition of a previous description of the Quebec Newborn Twin Study (QNTS; Boivin, Brendgen, Dionne et al., 2013). As the name entails, the QNTS is an ongoing prospective longitudinal follow-up of a birth cohort of twins born between 1995 and 1998 in the greater Montreal area. The goal of QNTS is to document individual differences in the cognitive, behavioral, social-emotional aspects of developmental health across childhood, their early genetic and environmental determinants, as well as their putative role in later social-emotional adjustment, school and health outcomes. A population-based sample of $>660$ families of twins were initially enrolled in QNTS, and then assessed longitudinally at regular intervals. The QNTS is part of a larger research initiative that also involves the Québec Longitudinal Study of Child Development (QLSCD), an ongoing longitudinal follow-up of a representative sample of $>2000$ children born as singletons in 1998 in the province of Québec, Canada. The QNTS and the QLSCD are companion studies sharing many features (measures and time of assessments), including an extensive and detailed set of evaluations in the early years, thus providing together a unique window into the role of early childhood in development.

Author for correspondence: Michel Boivin, Email: michel.boivin@psy.ulaval.ca.

Cite this article: Boivin M, Brendgen M, Dionne G, Ouellet-Morin I, Dubois L, Pérusse D, Robaey P, Tremblay RE, and Vitaro F. (2019) The Quebec Newborn Twin Study at 21. Twin Research and Human Genetics 22: 475-481, https://doi.org/10.1017/thg.2019.74

\section{Recruitment and Initial Assessment}

The recruitment phase of the QNTS was initiated in 1995 with the Québec Newborn Twin Registry, which identified all twin births occurring in the province of Québec between April 1995 and December 1998. Names, addresses, and phone numbers of all the mothers of newborn twins were collected from the computerized birth records of the Québec Bureau of Statistics. Recruitment and maintenance of families in the Registry was achieved through a series of periodic mail and telephone contacts, newsletters, and follow-ups. Starting June 1, 1996, all parents in the Registry who lived in seven administrative social health districts comprising and surrounding the Greater Montreal Area were asked to enroll with their twins in the QNTS. Parents were contacted by letter and by phone, and laboratory appointments were scheduled for when the twins were aged between 59 and 61 weeks from conception, or 5 months corrected for gestational age. A total of 989 families were contacted, of which 662 participated in the first wave (i.e., at age 6.3 months on average, $S D=.73$ ) between June 1996 and November 1998. A subgroup of these families of twins (with their mother) was seen in the lab (322 families) where extensive psychophysiological, hormonal, and observational-behavioral measures were collected. These laboratory assessments were followed within 2 weeks by a home visit to obtain exhaustive social, demographic, health, and further behavioral data on the twins and their families, 
Table 1. Participating twins in the longitudinal follow-up of the QNTS

\begin{tabular}{lcccc}
\hline Wave & $\begin{array}{c}\text { Mean age } \\
\text { (months) }\end{array}$ & SD & $\begin{array}{c}\text { No. of pairs complete/ } \\
\text { incomplete }\end{array}$ & $\begin{array}{c}\text { No. of } \\
\text { twins }\end{array}$ \\
\hline 6 months & 6.3 & .73 & $662 / 0$ & 1324 \\
\hline 20 months & 19.6 & .82 & $566 / 0$ & 1132 \\
\hline 32 months & 31.9 & .99 & $524 / 0$ & 1048 \\
\hline 50 months & 50.2 & 1.9 & $442 / 0$ & 884 \\
\hline 63 months & 63.5 & 3.3 & $446 / 0$ & 892 \\
\hline Kindergarten & 72.5 & 3.3 & $398 / 4$ & 800 \\
\hline Grade 1 & 84.9 & 3.2 & $474 / 2$ & 950 \\
\hline Grade 3 & 109.2 & 3.5 & $362 / 31$ & 755 \\
\hline Grade 4 & 120 & 3.4 & $432 / 12$ & 876 \\
\hline Grade 6 & 145.1 & 3.4 & $400 / 6$ & 806 \\
\hline Secondary 1 & 156.7 & 3.7 & $403 / 7$ & 813 \\
\hline Secondary 2 & 169.2 & 3.6 & $395 / 10$ & 800 \\
\hline Secondary 3 & 180.5 & 3.2 & $401 / 13$ & 815 \\
\hline Secondary 5 & 204.8 & 3.1 & $397 / 14$ & 808 \\
\hline Age 19 & 230.7 & 5.8 & $486 / 35$ & TBD \\
\hline Age 23 & TBD & TBD & & 1007 \\
\hline
\end{tabular}

Note: TBD, to be determined.

mainly through interview of both parents, self-reported questionnaires filled out by both parents, and direct observation of the infant, home, and neighborhood by the interviewer. Interviews were done in French or English, depending on the language of the respondents.

\section{Longitudinal Follow-Up}

As shown in Table 1, these twin children and their parents were then followed up longitudinally and assessed at 20 months (families seen in the lab at 5 months were again seen in the lab and at home; families seen only at home at 5 months were seen only at home), 32 months (home interview and questionnaires to parents only), 50 months (home interview and questionnaires to parents only), and then again the summer before school entry at 63 months (lab visit in the summer for a battery of cognitive measures), in kindergarten (average age 72 months: school-based assessments: experimental playgroup behavioral observations, cognitive assessments, peer and teacher assessments), grade 1 (age 85 months: similar to kindergarten), grade 3 (age 9.1 years: only teacher ratings), grade 4 (age 10 years: self-, peer/sociometric, and teacher assessments), and grade 6 (age 12 years: self- and teacher assessments, and questionnaires to parents). The twins and their families were then assessed on four occasions in secondary school, that is, in secondary 1 (age 13 years: self-assessments and questionnaires to parents), secondary 2 (age 14.1 years: self-assessments, extensive bio-sampling for cortisol, and questionnaires to parents), secondary 3 (age 15.1 years: home visit with direct assessment of twin and parent IQ, child reading and writing, mother language, web-based test battery of numeracy, self-assessments, and Person Most Knowledgeable [PMK] ratings of the twins), secondary 5 (age 17.1 years: self-assessments and questionnaires to parents, behavioral observation of impulsivity/executive control in lab settings, extensive self- and parent report of domain-specific school achievement, expectations regarding schooling).
Quite unique to QNTS are the longitudinal assessments of peer relations through sociometric interviews and peer ratings (i.e., classmates) in kindergarten, grades 1 and 4, as well as through self-reports from the twins' friends in secondary 1, 3, and 5 . Two other well-documented aspects of QNTS are the extended and thorough longitudinal assessments from preschool to early adulthood, of school readiness and achievement, as well as of social behaviors and mental health symptoms. QNTS is now well into the postsecondary (i.e., post high school) period, and the twins have already been surveyed once, around the age of 19 years (ages between 18 and 22 years: through web-based assessments and bio-sampling). A new data collection, planned around the age of 23 , will be aligned with the web-based assessments at age 19 .

\section{Participation}

From the original 1324 participating twins, the number of participants fell to 1132 and 1048 twins in next two waves (20 and 32 months, respectively), and to 884 and 892 twins at the end of preschool (50 and 63 months, respectively). Then, from kindergarten to the end of grade school, the number of participating twins stabilized (see Table 1). At age 19, many twins lost in the follow-up were contacted again through a comprehensive search-and-contact initiative, with the result of a substantial raise in the number of participants (1007 twins from 521 families).

\section{Longitudinal Measures of Child Phenotypes}

Over these years, participants were assessed longitudinally on a broad range of characteristics through multi-informant (mothers, fathers, caregivers, teachers, age-peers, raters) and multimethod measurements (behavior ratings, semi-structured interviews, interactive interviews, peer assessments, direct observation). Whenever possible, a 'blind' procedure was used through which assessments were administered and rated by research personnel who were not exposed to both members of a twin pair, reducing potential biases related to the perceived zygosity of subjects. At each assessment time, computerized face-to-face interviews of the PMK about the child (usually the mother in the early years) were conducted.

Regular assessments also included questionnaires completed by the mother, the father, and the interviewer, and longitudinal direct and multifaceted assessments of cognitive development, with a strong emphasis on school readiness at 63 months and in kindergarten (e.g., literacy, vocabulary, numeracy, general IQ). School achievement, especially regarding the ' 3 Rs' (reading, writing, and arithmetic), was assessed at each time point of grade school, and was supplemented in grade 2 (age 100 months; see below) by direct measures of reading and its determinants, and then in secondary 3 (age 15.1 years) by direct assessments of IQ, vocabulary, reading, and writing, as well as of numeracy.

Social behaviors and mental health symptoms were assessed yearly from 20 months on, through PMK, spouse and interviewer ratings, teacher ratings (in primary school), and self-ratings (starting at the end of primary school, and then in secondary school). We used a variant of the Child Social Behavior Questionnaire, which centers on externalizing behaviors such as hyperactivity, impulsivity, inattention, aggression, as well as on internalizing behaviors, such as shyness, social withdrawal, anxiety, and depression symptoms. In secondary school, the self-ratings also covered substance use, delinquency, and gambling (longitudinally from secondary 1 to 5), sexual behaviors, in addition to psychological adjustment. Behavior observations were conducted in a controlled 
setting when the twins were aged 6 and 20 months, in kindergarten, and then later in secondary 5 (age 17) for impulsivity and executive control.

Glucocorticoid stress hormone cortisol samples were collected at 6,20,63 months, kindergarten, 100 months (age 8.2), age 14 (secondary 2), as well as at age 19 , typically using salivary samples under basal, daily or reactive conditions, with the exception of age 19 wave, where hair samples were collected. At age 19, self-efficacy measures pertaining to a variety of domains (behavioral, social, academic, work-related) were also included.

\section{Longitudinal Measures of the Child's Environment}

The QNTS also entails extended and detailed multilevel assessments of proximal (e.g., parenting behaviors, peer relations, and friends' characteristics) and distal (e.g., family income) features of the child's environment across development. Parenting behaviors were assessed yearly in preschool, starting at 5 months, through mother and father self-reports of parental warmth, self-efficacy and perceived impact, overprotection, and hostile-reactive behavior, as well as later in adolescence (ages 15 and 17). Also starting at 5 months were early family (i.e., parents') literacy practices.

Peer relationships and experiences (e.g., peer rejection and victimization) were assessed in kindergarten, in grade 1 , and in grade 4 through peer assessments and classroom sociometric interviews, a unique feature for a population-based study of this scale (see below for details). The quality of friendships, and the characteristics of friends, were also assessed longitudinally in kindergarten, and grades 1 and 4 of elementary school, as well as in secondary 1,3 , and 5 (i.e., once identified, the friends filled out questionnaires about themselves and their relationship with the target twin; see below). In addition, the twins' perceived quality of the relationship with each parent and between the two twins was assessed at each wave, starting in grade 4 . Starting in secondary 1 , measures pertaining to romantic relationships were added. Other putative measures of the child environment collected regularly are about nutrition (see below), mental health status of parents, marital satisfaction and status, as well as a variety of socioeconomic and demographic characteristics (e.g., family income and parents' education).

\section{Additional Data Collection}

In addition to the 16 regular data collections, the QNTS was supplemented with unique ad hoc data collections aimed at:

(1) Prenatal and perinatal health. Medical records are available for 613 families of twins, and were supplemented with mother report when the twins were 6 months old, allowing for the assessment of specific prenatal and perinatal risk factors, including maternal smoking (about $26 \%$ of the mothers smoked during pregnancy), drinking or substance abuse during pregnancy (32\% had alcohol at least once, $9 \%$ more than once, $3 \%$ more than once per week), newborn's birth weight ( $47 \%$ of the twins were born low birth weight, i.e., $<2.5 \mathrm{~kg} ; 5 \%$ as very low birth weight, i.e., $<1.5 \mathrm{~kg}$ ), APGAR score (i.e., an indication of child health at birth, muscle tone, reflex, breathing) at 1 and $5 \mathrm{~min}$, hospital length of stay, type of birth (C-section), gestational diabetes, preeclampsia and hypertension during pregnancy, gestational age at delivery, and hypoxia.

(2) Genotyping. For the purpose of genotyping, blood and saliva samples were initially collected from the twins and their parents for a subsample of QNTS families when the twins were approximately 100 months of age, and then again (only saliva this time) when the twins were aged 19. Genotyping was successfully obtained for 407 parents and 581 twins (including $136 \mathrm{MZ}$ twins) in the first wave (at 100 months of age), and for an additional 328 twins (including $38 \mathrm{MZ}$ twins) in the second wave (at age 19) for a total of 909 twins. Genotyping was performed using Illumina's Psycharray Beadchip, which, after appropriate quality control and imputation procedures, will enable the calculation of a variety of polygenic scores pertaining to the study's objectives (e.g., EduYears-3), and the testing of specific gene-environment interplay.

(3) Epigenotyping. At age 19 years, saliva samples were collected from 877 twins using the Purirtan ${ }^{\mathrm{TM}}$ Foam Tipped Swabs (Fisher-Scientific). These samples are currently being processed for DNA extraction, quality control, and DNA methylation profiling with the HumanMethylationEPIC DNA analyses BeadChip Kit (Illumina, San Diego, California). This profiling allows for the measurement of approximately 860,000 CpGs, with the goal of identifying associations of differentially methylated loci in participants with (1) their past exposition to specific environments, as well as with (2) health problems in adulthood. This dual characterization through both GWAS and EWAS is a first step toward an integrated multi-omic approach to the etiology of developmental health. Accordingly, dried blood spots were also collected at 19 years of age, with the goal of documenting a series of pro- and anti-inflammatory cytokine (e.g., interleukin-6 and tumor necrosis factor- $\alpha$ ), immune (e.g., C-reactive protein and fibrinogen), and metabolic biomarkers (e.g., high-density lipoprotein cholesterol, triglycerides, total cholesterol). All of this will allow for a more thorough investigation into the possible physiological 'wear and tear' mechanisms (e.g., the allostatic load) linking early adversity and future health.

(4) Peer assessment and sociometric. In kindergarten, and then in grades 1 and 4, the participating twins' schools and classrooms were identified. With the authorized consents of the school boards, school directors, teachers, and parents, the classmates of each twin were asked to participate in a peer nomination task, as well as to fill out a short questionnaire about their behavior. Using booklets of photographs, the participating children were asked to nominate three classmates for each of a series of behavioral and social descriptors. This information could then be used to assess: (1) the degree to which the twins were liked/disliked by their peers and (2) were victimized by their peers, (3) the twin's behavior (e.g., aggressive, hyperactive, inattentive, impulsive, withdrawn, shy, or leadership) as perceived by their peers, as well as identify the classmates who were their friends. In kindergarten, there were 569 participating classrooms in 325 schools, with an average of 14 'nominating' children per class (30\% of the twins were in the same class). In grade 1, the numbers were 636 classrooms in 362 schools, with an average of 14 'nominating' children per class ( $23 \%$ of the twins were in the same class). Finally, in grade 4, peer assessments were done in 581 classrooms in 348 schools, with an average of 19 'nominating' children per class $(28 \%$ of the twins were in the same class). This rich information is a unique feature of QNTS and provides a unique window into the quality of the twins' peer experiences, as well as of their social behavior as perceived by their classmates.

(5) Friendships. The quality of friendships and the characteristics of friends were also assessed longitudinally from kindergarten to grade 4; twins were asked to nominate up to three friends in their classroom, and these friends' behavior and social status were rated by their classmates and teacher. Both friends and twins reported on the quality of their relationship. When the twins were aged 13, 
15 , and 17 , they also nominated up to six friends (on average, twins nominated on average between 1.5 age-13 and 2.5 age- 17 friends); these friends were then invited to fill out the same questionnaires as the twins.

(6) Nutrition. In addition to nutrition and body weight data regularly collected over the years (e.g., breastfeeding, eating behaviors), a detailed nutrition survey was done with the twins when they were approximately 9 years of age. Nutrition data were collected with a 24 -h recall, repeated two times on separate days (including one weekend day) by trained nutritionists using wooden volume models to estimate portion size (Hill \& Davies, 2001). From this database, energy, carbohydrates, fat, protein, vitamins and minerals, and food group consumption was estimated.

(7) Neuropsychological assessments. As part of a project aimed at documenting the neuropsychological underpinnings of early inattention, impulsiveness, and restlessness, a subsample of 150 pairs of QNTS were seen in the lab when they were aged about 100 months between April 2004 and April 2006. These QNTS twins were probed for the presence of symptoms of inattention, impulsiveness, and hyperactivity, and assessed through a battery of different neuropsychological tests, including a mixed go/nogo and stop task (measuring both restrain and cancellation in a single paradigm), continuous performance task (oddball), and a visuospatial working memory task. Their brain electrical activity was also recorded using a large array of electrodes (EEG/ERP) during these tests, and brain anatomical magnetic resonance imaging data was collected. Then, when the twins were aged about 17 (secondary 5), all participating twins were assessed again for impulsivity/executive control through various task-behavioral observations in lab settings, including the go/no-go, card playing task, Tower of London task, and delay of discounting tasks.

(8) Mathematical abilities and number sense. In addition to measures of early numeracy (number knowledge), and mathematical achievement and motivation, regularly collected in QNTS, a web-based test battery developed as part of the Twins Early Development Study (Robert Plomin, director), adapted and validated for international administration by the International Laboratory for Interdisciplinary Investigations into Individual Differences in Learning (in-Lab, Goldsmith College, University of London; Dr Yulia Kovas, director), was administered to the QNTS twins at the end of secondary 3, when the twins were aged 15. This battery of seven tasks covered a wide range of abilities that underlie number sense and mathematical skills, including tests of mathematical achievement (math test) and fluency (problem verification task), speed of processing (reaction time to numerical stimuli), visuospatial working memory (Corsi tapping block), and number sense (number line; dot task measuring numerosity; dot matching measuring visual matching). This battery is now being used in different cohorts internationally, including in Russia, the United Kingdom (London), the United States (Ohio), and Kyrgyzia. A total of 694 twins (330 complete pairs and 34 singletons) of QNTS completed at least part of the battery.

(9) Gambling and substance use in adolescence. The frequency of substance use (alcohol, marijuana, other drugs) was assessed at ages 13,14,15, 17, and 19 through the use of the Personal Experience Screening Questionnaire (Henly \& Winters, 1989). Participation in gambling activities was assessed during the same times with the South Oaks Gambling Screen for adolescents (SOGS-RA; Winters et al., 1993).

(10) Academic aspirations, higher education, and occupational experiences. Starting in secondary 5 , twins and their parents were asked about the twins' academic aspirations and achievement, as well as their perceived satisfaction regarding support from parents and teachers in grade school, college, and university. Twins reported on their career aspirations, their occupational status (i.e., actual job if any), as well as on the quality of their relationships with their work companions. Also collected at age 19 were measures of perceived victimization within the workplace and educational settings (e.g., college).

\section{Zygosity Assessment}

Zygosity was ascertained through the analysis of genetic markers for same-sex twin pairs, supplemented by diagnoses based on physical similarity when genetic diagnoses were inconclusive or could not be obtained. Eight or nine highly polymorphic genetic markers were used for genotyping. Any difference between the twins of a pair resulted in a DZ diagnosis. The twins were diagnosed MZ when concordant for every genetic marker. The diagnosis of zygosity based on genetic marker analysis can be considered certain. The genetic marker analysis could not be made for twins who drop out of the study early and for twins for whom parents refused consent. In some cases, the genetic material was insufficient for genotyping. In these cases, the pairs were diagnosed mainly on the basis of a shortened version of Goldsmith's Zygosity Questionnaire for Young Twins (Goldsmith, 1991) at 5 and 18 months. When compared with the diagnoses obtained by genetic marker analysis in a subsample of 237 same-sex pairs, the diagnoses based on physical similarity were accurate in $92 \%$ of the cases at 5 months and in $94 \%$ of cases at 19 months. Supplemented with chorionicity data, the accuracy rate climbed to $96 \%$ (Forget-Dubois et al., 2003). The final zygosity diagnosis for all same-sex pairs was constructed this way: (1) If a diagnosis by genetic marker analysis was available, it is considered the final diagnosis. (2) In the absence of a diagnosis based on genetic marker analysis, the final zygosity diagnosis is based on physical similarity at 5 and 18 months supplemented whenever possible by data on blood group and chorionicity. The diagnoses based only on physical similarity were re-evaluated in April 2007 with physical similarity questionnaires (adapted from Spitz et al., 1996) answered by the parents during a brief telephonic interview. A final diagnosis indicated that QNTS consisted of 254 pairs of MZ twins (125 boy pairs and 129 girl pairs), 210 pairs of same-sex DZ twins (105 boy pairs and 105 girl pairs), and 203 pairs of opposite-sex DZ twins.

\section{Scientific Contributions}

The QNTS is uniquely suited to document the genetic and environmental etiology of a variety of phenotypes early in development as well as longitudinally. Here are a few examples of QNTS-based contributions.

We have documented the genetic and environmental contributions to a variety of behavioral, educational, and health outcomes, as well as their associations, including different forms and functions of aggressive behaviors, such as reactive versus proactive versus social aggression (Brendgen et al., 2005, 2006; Paquin et al., 2017), early physical aggression and language (Dionne et al., 2003), early numeracy and later achievement in mathematics (Garon-Carrier et al., 2017), early sleep patterns and language development (Dionne et al., 2011; Touchette et al., 2013), attention-deficit/ hyperactivity and reading (Plourde et al., 2015, 2017), gambling and substance use (Vitaro et al., 2014, 2018), callous-unemotional traits and fear recognition (Petitclerc et al., 2019), as well as more basic endophenotypes such as cortisol (Ouellet-Morin et al., 2016) and 
response inhibition (Schachar et al., 2011). We also showed that the stability of various social behaviors, such as disregard for rules (a central component of early opposition), physical aggression, callous-unemotional traits, and shyness, was more highly, and often quite substantially associated with genetic factors than their episodic manifestations (Henry, Dionne, Viding, Petitclerc et al., 2018; Lacourse et al., 2014; Morneau-Vaillancourt et al., 2019; Petitclerc et al., 2011).

In contrast, cognitive school readiness before school entry was more strongly accounted for by environmental factors shared and uniquely experienced by children of the same family. Cognitive school readiness was highly predictive of school achievement in the early grades of primary school, and this predictive association was also substantially accounted for by shared and unique environmental factors (Lemelin et al., 2007; see also Vitaro et al., 2012). We have provided evidence for the central role of early literacy training (i.e., parent reading to the child) in accounting for the link between socioeconomic status and school readiness (Forget-Dubois et al., 2009), as well as shown how gestational diabetes may specifically hinder early language development (Dionne et al., 2008). This ongoing line of research clearly indicates that school readiness and achievement are to a significant extent environmentally mediated and have their roots in early development (see also Garon-Carrier et al., 2017).

Thanks to the detailed longitudinal information about the twins' development and their (measured) environment, the QNTS is uniquely suited for the investigation of gene-environment transactions in development, such as gene-environment correlations and gene $\times$ environment interaction processes. Many scientific contributions of QNTS are along those lines. For example, a series of studies on the genetic and environmental determinants of early (i.e., 5 and 18 months) vulnerability to stress regulation has provided evidence for a complex pattern of time-dependent gene-by-environment interaction in the cortisol response (Ouellet-Morin et al., 2008, 2009). These patterns indicate that the role of genes in the stress response varies as a function of family adversity, but in an developmentally coherent way over time; significant heritability was found only in the presence of family adversity at 6 months, but a reverse pattern was revealed at 18 months (i.e., heritability in the absence of adversity, and no heritability in the presence of adversity). This pattern suggests an evolving process of gene $x$ environment interaction in the stress response, and is quite consistent with a programming effect of the environment (possibly through parenting) superseding genetic influence at 18 months. This exciting new line of research is ongoing, and we are currently examining cortisol samples collected later in QNTS to see whether this pattern is maintained, to document the possible early family mediators of these patterns (i.e., parenting), and to examine the nature of the association between peer difficulties, stress response, and psychological adjustment (Brendgen et al., 2017).

Parenting and peer relationships are indeed well documented in QNTS. With respect to parenting, we have documented the presence of a gene-environment correlation linking child's difficult temperament and harsh-reactive parenting behaviors at 6 months of age (Boivin et al., 2005), but not later, over the 6-32-month period (Forget-Dubois et al., 2007). Positive parenting was also found to moderate genetic contribution to callous-unemotional traits in childhood (Henry, Dionne, Viding, Vitaro et al., 2018).

As indicated earlier, peer relationships are perhaps the best documented features of the twins' environment in QNTS. Taking advantage of this longitudinal information, we found that peer relationship difficulties, while substantially associated with genetic vulnerabilities through evocative gene $\times$ environment correlations (Boivin, Brendgen, Vitaro, Dionne et al., 2013; Boivin, Brendgen, Vitaro, Forget-Dubois et al., 2013), also interact in complex ways with aggressive behaviors, psychological adjustment, and context across development (Brendgen et al., 2009, 2011, 2015; Brendgen, Boivin, Vitaro, Girard et al., 2008). Gene $\times$ environment interaction processes were also revealed for the moderating role of friendship in behavior problems, peer relation difficulties, and personal adjustment in the early years of school (Brendgen, Boivin, Vitaro, Bukowski et al., 2008; Brendgen et al., 2013; van Lier et al., 2007). For example, we found that genetic vulnerabilities and befriending other aggressive children were independently associated with aggressive behaviors in kindergarten, but also that having an aggressive friend contributed more to aggression in children who are genetically at risk of aggression than for children who were not, thus suggesting a gene $\times$ environment interaction (van Lier et al., 2007). This pattern was also confirmed among first-graders (Brendgen, Boivin, Vitaro, Bukowski et al., 2008).

This non-exhaustive review of some of the most important scientific contributions of QNTS illustrates the potential of this database to elucidate the gene-environment processes underlying the early biosocial determinants of various cognitive, behavioral, and social-emotional components of developmental health across childhood, as well as their role in later social-emotional adjustment, school, and health outcomes. This work is laying the foundation for further interdisciplinary and international collaborations around QNTS on these issues (e.g., Kovas et al., 2015; Silventoinen et al., 2015, 2016).

\section{Future Directions}

Subsequent to our last report (Boivin, Brendgen, Dionne et al., 2013), QNTS has recently added new data collections. As indicated previously, we are now planning a next data collection when the twins will be about 23 years old, that is, well into their young adult life. After the regular school-based waves, the follow-ups (i.e., involving a personal contact with the twins) will be more spaced and rely more on a web-based approach, with sporadic lab assessments. In addition, there will be a strong emphasis on collecting information through administrative records (e.g., education, health, social welfare, and criminal records) to further document the role of childhood factors in developmental health and human capital. As the participating twins will establish families and start having children, we aim to document their parenting, their family relations, as well as their children's development to understand intergenerational transmission processes. So far, QNTS has produced $>95$ papers in leading international scientific journals. This production is now expanding as the study reaches its maturity. The challenge in the coming years will be to take full advantage of the wealth of QNTS data, including various new polygenic scores, to significantly advance our understanding of gene-environment interplay in developmental health.

Acknowledgments. We are grateful to the children and parents of the QNTS, and the participating teachers and schools. We thank Jocelyn Malo and MarieÉlyse Bertrand for coordinating the data collection, as well as Hélène Paradis and Nadine Forget-Dubois for managing the databank of QNTS. We also thank Guy Rouleau and Cathy Barr for the genotyping of the twins, and Yulia Kovas and Robert Plomin for allowing us the use their web-based numeracy battery. This research was supported by many grants received over the years by the authors of this paper. These grants were from the Fonds Québécois de la Recherche sur la Société et la Culture (FQRSC), the Fonds de la Recherche en Santé du Québec (FRSQ), the Social Science and Humanities Research 
Council of Canada, the National Health Research Development Program, the Canadian Institutes for Health Research, Ste. Justine Hospital's Research Center, Université Laval, and Université de Montréal. Michel Boivin and Isabelle Ouellet-Morin are supported by the Canada Research Chair Program.

\section{References}

Boivin, M., Brendgen, M., Dionne, G., Dubois, L., Pérusse, D., Robaey, P., . . Vitaro, F. (2013). The Quebec newborn twin study into adolescence: 15 years later. Twin Research and Human Genetics, 16, 64-69.

Boivin, M., Brendgen, M., Vitaro, F., Dionne, G., Girard, A., Pérusse, D., . . Tremblay, R. E. (2013). Strong genetic contribution to peer relationship difficulties at school entry: Findings from a longitudinal twin study. Child Development, 84, 1098-1114.

Boivin, M., Brendgen, M., Vitaro, F., Forget-Dubois, N., Feng, B., Tremblay, R. E., . . Dionne, G. (2013). Evidence of gene-environment correlation for peer difficulties: Disruptive behaviors predict early school peer relation difficulties through genetic effects. Development and Psychopathology, 25, 79-92.

Boivin, M., Pérusse, D., Dionne, G., Saysset, V., Zoccolillo, M., Tarabulsy, G. M., ... Tremblay, R. E. (2005). The genetic-environmental etiology of parents' perceptions and self-assessed behaviours toward their 5-months-old infants in a large twin and singleton sample. Journal of Child Psychology and Psychiatry, 46, 612-630.

Brendgen, M., Boivin, M., Dionne, G., Barker, E. D., Vitaro, F., Girard, A., . . Pérusse, D. (2011). Gene-environment processes linking aggression, peer victimization, and the teacher-child relationship. Child Development, 82, 2021-2036.

Brendgen, M., Boivin, M., Vitaro, F., Bukowski, W. M., Dionne, G., Tremblay, R. E., \& Pérusse, D. (2008). Linkages between children's and their friends' social and physical aggression: Evidence for a gene-environment interaction? Child Development, 79, 13-29.

Brendgen, M., Boivin, M., Vitaro, F., Girard, A., Dionne, G., \& Pérusse, D. (2008). Gene-environment interaction between peer victimization and child aggression. Development and Psychopathology, 20, 455-471.

Brendgen, M., Dionne, G., Girard, A., Boivin, M., Vitaro, F., \& Pérusse, D. (2005). Examining genetic and environmental effects on social aggression: A study of 6-year-old twins. Child Development, 76, 930-946.

Brendgen, M., Girard, A., Vitaro, F., Dionne, G., \& Boivin, M. (2015). Gene-environment correlation linking aggression and peer victimization: Do classroom behavioral norms matter? Journal of Abnormal Child Psychology, 43, 19-31.

Brendgen, M., Ouellet-Morin, I., Lupien, S., Vitaro, F., Dionne, G., \& Boivin, M. (2017). Does cortisol moderate the environmental association between peer victimization and depression symptoms? A genetically informed twin study. Psychoneuroendocrinology, 84, 42-50.

Brendgen, M., Vitaro, F., Boivin, M., Dionne, G., \& Pérusse, D. (2006). Examining genetic and environmental effects on reactive versus proactive aggression. Developmental Psychology, 42, 1299-1312.

Brendgen, M., Vitaro, F., Boivin, M., Girard, A., Bukowski, W. M., Dionne, G., ... Pérusse, D. (2009). Gene-environment interplay between peer rejection and depressive behavior in children. Journal of Child Psychology and Psychiatry, 50, 1009-1017.

Brendgen, M., Vitaro, F., Bukowski, W. M., Dionne, G., Tremblay, R. E., \& Boivin, M. (2013). Can friends protect genetically vulnerable children from depression? Development and Psychopathology, 25, 277-289.

Dionne, G., Boivin, M., Séguin, J. R., Pérusse, D., \& Tremblay, R. E. (2008). Gestational diabetes hinders language development in offspring. Pediatrics, 122, e1073-e1079.

Dionne, G., Boivin, M., Tremblay, R. E., Laplante, D., \& Pérusse, D. (2003). Physical aggression and expressive vocabulary in 19-month-old twins. Developmental Psychology, 39, 261-273.

Dionne, G., Touchette, E., Forget-Dubois, N., Petit, D., Tremblay, R. E., Montplaisir, J. Y., \& Boivin, M. (2011). Association between sleep-wake consolidation and language development in early childhood: A longitudinal twin study. Sleep, 34, 987-995.

Forget-Dubois, N., Boivin, M., Dionne, G., Pierce, T., Tremblay, R. E., \& Pérusse, D. (2007). A longitudinal twin study of the genetic and environmental etiology of maternal hostile-reactive behavior during infancy and toddlerhood. Infant Behavior \& Development, 30, 453-465.

Forget-Dubois, N., Dionne, G., Lemelin, J.-P., Pérusse, D., Tremblay, R. E., \& Boivin, M. (2009). Early child language mediates the relation between home environment and school readiness. Child Development, 80, 736-749.

Forget-Dubois, N., Pérusse, D., Turecki, G., Girard, A., Billette, J.-M., Rouleau, G., .. Tremblay, R. E. (2003). Diagnosing zygosity in infant twins: Physical similarity, genotyping, and chorionicity. Twin Research, 6, 479-485.

Garon-Carrier, G., Boivin, M., Kovas, Y., Feng, B., Brendgen, M., Vitaro, F., ... Dionne, G. (2017). Persistent genetic and family-wide environmental contributions to early number knowledge and later achievement in mathematics. Psychological Science, 28, 1707-1718.

Goldsmith, H. H. (1991). A zygosity questionnaire for young twins: A research note. Behavior Genetics, 21, 257-269.

Henly, G. A., \& Winters, K. C. (1989). Development of psychosocial scales for the assessment of adolescent involved with alcohol and drugs. The International Journal of the Addictions, 24, 973-1001.

Henry, J., Dionne, G., Viding, E., Petitclerc, A., Feng, B., Vitaro, F., ... Boivin, M. (2018). A longitudinal twin study of callous-unemotional traits during childhood. Journal of Abnormal Psychology, 127, 374-384.

Henry, J., Dionne, G., Viding, E., Vitaro, F., Brendgen, M., Tremblay, R. E., \& Boivin, M. (2018). Early warm-rewarding parenting moderates the genetic contributions to callous-unemotional traits in childhood. Journal of Child Psychology and Psychiatry, 59, 1282-1288.

Hill, R. J., \& Davies, P. S. W. (2001). The validity of self-reported energy intake as determined using the doubly labelled water technique. British Journal of Nutrition, 85, 415-430.

Kovas, Y., Garon-Carrier, G., Boivin, M., Petrill, S. A., Plomin, R., Malykh, S. B., ... Vitaro, F. (2015). Why do children differ in motivation to learn: Insights from over 13,000 twins from 6 countries. Personality and Individual Differences, 80, 51-63.

Lacourse, E., Boivin, M., Brendgen, M., Petitclerc, A., Girard, A., Vitaro, F., ... Tremblay, R. E. (2014). A longitudinal twin study of physical aggression during early childhood: Evidence for a developmentally dynamic genome. Psychological Medicine, 44, 2617-2627.

Lemelin, J.-P., Boivin, M., Forget-Dubois, N., Dionne, G., Séguin, J. R., Brendgen, M., . . Pérusse, D. (2007). The genetic-environmental etiology of cognitive school readiness and later academic achievement in early childhood. Child Development, 78, 1855-1869.

Morneau-Vaillancourt, G., Dionne, G., Brendgen, M., Vitaro, F., Feng, B., Henry, J., . . Boivin, M. (2019). The genetic and environmental etiology of shyness through childhood. Behavior Genetics, 49, 376-385.

Ouellet-Morin, I., Boivin, M., Dionne, G., Lupien, S. J., Arsenault, L., Barr, R. G., ... Tremblay, R. E. (2008). Variations in heritability of cortisol reactivity to stress as a function of early familial adversity among 19-monthold twins. Archives of General Psychiatry, 65, 211-218.

Ouellet-Morin, I., Brendgen, M. R., Girard, A., Lupien, S., Dionne, G., Vitaro, F., \& Boivin, M. (2016). Evidence of a unique and common genetic etiology between the CAR and the remaining part of the diurnal cycle: A study of 14 year-old twins. Psychoneuroendocrinology, 66, 91-100.

Ouellet-Morin, I., Dionne, G., Pérusse, D., Lupien, S., Arseneault, L., Barr, R. G., .. Boivin, M. (2009). Daytime cortisol secretion in 6-month-old twins: Genetic and environmental contributions as a function of early familial adversity. Biological Psychiatry, 65, 409-416.

Paquin, S., Lacourse, E., Brendgen, M., Vitaro, F., Dionne, G., Tremblay, R. E., \& Boivin, M. (2017). Heterogeneity in the development of proactive and reactive aggression in childhood: Common and specific geneticenvironmental factors. Plos One, 12, e0188730.

Petitclerc, A., Boivin, M., Dionne, G., Pérusse, D., \& Tremblay, R. E. (2011). Genetic and environmental etiology of disregard for rules. Behavior Genetics, $41,192-200$

Petitclerc, A., Henry, J., Feng, B., Poliakova, N., Brendgen, M., Dionne, G., . . . Boivin, M. (2019). Genetic correlation between child callous-unemotional behaviors and fear recognition deficit: Evidence for a neurocognitive endophenotype. Journal of Abnormal Child Psychology, 47, 1483-1493.

Plourde, V., Boivin, M., Brendgen, M., Vitaro, F., \& Dionne, G. (2017). Phenotypic and genetic associations between reading and attention-deficit/ 
hyperactivity disorder dimensions in adolescence. Development and Psychopathology, 29, 1215-1226.

Plourde, V., Boivin, M., Forget-Dubois, N., Brendgen, M., Vitaro, F., Marino, C., ... Dionne, G. (2015). Phenotypic and genetic associations between reading comprehension, decoding skills, and ADHD dimensions: Evidence from two population-based studies. Journal of Child Psychology and Psychiatry, 56, 1074-1082.

Schachar, R. J., Forget-Dubois, N., Dionne, G., Boivin, M., \& Robaey, P. (2011). Heritability of response inhibition in children. Journal of the International Neuropsychological Society, 17, 238-247.

Silventoinen, K., Jelenkovic, A., Sund, R., Honda, C., Aaltonen, S., Yokoyama, Y., ... Kaprio, J. (2015). The CODATwins Project: The cohort description of collaborative project of development of anthropometrical measures in twins to study macro-environmental variation in genetic and environmental effects on anthropometric traits. Twin Research and Human Genetics, 18, 348-360.

Silventoinen, K., Jelenkovic, A., Sund, R., Hur, Y.-M., Yokoyama, Y., Honda, C., ... Kaprio, J. (2016). Genetic and environmental effects on body mass index from infancy to the onset of adulthood: An individual-based pooled analysis of 45 twin cohorts participating in the COllaborative project of Development of Anthropometrical measures in Twins (CODATwins). American Journal of Clinical Nutrition, 104, 371-379.

Spitz, E., Moutier, R., Reed, T., Busnel, M. C., Marchaland, C., Robertoux, P. L., \& Carlier, M. (1996). Comparative diagnoses of twin zygosity by SSLP variant analysis, questionnaire, and dermatoglyphic analysis. Behavior Genetics, 26, 55-63.

Touchette, E., Dionne, G., Forget-Dubois, N., Petit, D., Pérusse, D., Falissard, B., ... Montplaisir, J. Y. (2013). Genetic and environmental influences on daytime and nighttime sleep duration in early childhood. Pediatrics, 131, 1874-1880.

van Lier, P. A. C., Boivin, M., Dionne, G., Vitaro, F., Brendgen, M., Koot, H., . . Pérusse, D. (2007). Kindergarten children's genetic vulnerabilities interact with friends' aggression to promote children's own aggression. Journal of the American Academy of Child and Adolescent Psychiatry, 46, 1080-1087.

Vitaro, F., Boivin, M., Brendgen, M., Girard, A., \& Dionne, G. (2012). Social experiences in kindergarten and academic achievement in grade 1: A monozygotic twin difference study. Journal of Educational Psychology, 104, 366-380.

Vitaro, F., Dickson, D. J., Brendgen, M., Laursen, B., Dionne, G., \& Boivin, M. (2018). The gene-environmental architecture of the development of adolescent substance use. Psychological Medicine, 48, $2500-2507$.

Vitaro, F., Hartl, A. C., Brendgen, M., Laursen, B., Dionne, G., \& Boivin, M. (2014). Genetic and environmental influences on gambling and substance use in early adolescence. Behavior Genetics, 44, 347-355.

Winters, K. C., Stinchfield, R., \& Fulkerson, J. (1993). Patterns and characteristics of adolescent gambling. Journal of Gambling Studies, 9, 371-386. 
This article has been published in a revised form in Twin Research and Human Genetics

[doi:10.1017/thg.2019.74]. This version is free to view and download for private research and study only. Not for re-distribution or re-use. (C) Twin Research and Human Genetics. 